\title{
Construindo identidades: estado social cubano
}

\author{
Marianna Grigorievna Abramova \\ Academia das Finanças junto ao Governo da Federaçáo da Rússia \\ Quero que a principal Lei de nossa República seja um \\ profundo respeito dos cubanos pela dignidade humana \\ em toda a sua plenitude
}

José Martí

Introdução

O ano de 2009 teve um início muito simbólico. Com a crise econômica e financeira ganhando força, a comunidade internacional celebrou, no dia primeiro de janeiro, os cinquenta anos da Revoluçáo Cubana, e, em 21 de janeiro, os 85 anos da morte de Vladimir Ilitch Lênin, líder da Grande Revoluçáo de Outubro da Rússia. Terá perecido a causa de Lênin, 85 anos depois de sua morte? Náo, antes pelo contrário: é evidente para qualquer pesquisador imparcial que o modelo liberal de desenvolvimento social imposto ao mundo chegou a um impasse. $\mathrm{O}$ atraso tecnológico, crescente a cada ano, dos países em desenvolvimento, o hiato, cada vez maior, entre os países ricos e os países pobres, o fenômeno de marginalizaçăo social nos próprios países abastados que compóem o "bilháo dourado" colocam, mais do que em qualquer outro tempo, na ordem do dia a busca de alternativas sociais e de outros modelos de desenvolvimento. Nesse sentido, é, sem dúvida, interessante a experiência prática de Cuba na soluçăo de problemas sociais e na construçâo de um Estado social moderno. Desde a vitória da Revoluçấo de 1959, Cuba tem lutado pela justiça social, pela dignidade humana e pelos progressos socioeconômicos. "Enquanto houver, pelo menos, uma manifestaçáo da injustiça social, a Revolução nảo pode ser dada como terminada"1 - assinala o programa do "Movimento 26 de Julho".

O modelo de socialismo cubano foi bem-sucedido nas décadas de 1970 e de 1980 do século XX, sobreviveu à desagregaçáo do sistema socialista da década de 1990 e continua evoluindo de forma progressiva nos últimos anos. Como os cubanos conseguiram manter o regime econômico e social, estabelecido na ilha em 1959, e resistir aos choques econômicos, políticos e ideológicos que 
levaram à ruína toda uma série de países mais desenvolvidos como a RDA, a URSS e a Iugoslávia? Muitos poderão dizer que a questão está no líder, Fidel Castro no caso. É verdade, o papel dessa figura carismática, que pode reconhecer os erros cometidos, os corrigir e tomar decisóes extraordinárias, é grande.

Mas acho que as causas disso săo muito mais profundas. $\mathrm{O}$ modelo de socialismo cubano pode ser definido como nacionalista e o Estado, surgido em consequência da Revoluçáo de 1959, uma versáo moderna de um Estado socialista. A Revolução cubana náo pode ser vista, em nenhuma circunstância, como exportaçâo da revolução, pois amadureceu e tomou corpo no solo nacional. Iniciada como nacional democrática, a Revoluçáo cubana virou socialista. Como resultado, Cuba realizou uma reforma agrária, acabou com o latifundiarismo e a dependência do capital estrangeiro, procedeu à industrializaçáo e à diversificaçāo da economia nacional. Entre 1959 e 1989, o PIB de Cuba aumentou mais de 3,5 vezes, crescendo anualmente a uma taxa de 4,6\% enquanto nos outros países da América Latina esse índice foi de 1,8\% ${ }^{2}$. $\mathrm{O}$ processo de crescimento do $\mathrm{PIB}$ em si não é importante. $\mathrm{O}$ importante é seu impacto social. Em Cuba, o crescimento do PIB foi acompanhado da distribuiçắo regular da receita entre os cidadãos cubanos com vistas à satisfaçáo de suas necessidades fundamentais de natureza existencial, material e cultural e à elevaçáo dos padróes de qualidade de vida. Antes da Revoluçáo, $90 \%$ dos cubanos eram analfabetos totais ou funcionais. Hoje em dia, Cuba apresenta o alfabetismo universal. Antes da Revoluçáo, a expectativa média de vida mal chegava a 55 anos. Atualmente está em 78 anos e deve atingir 85 anos em 2025. Cuba mantém a liderança entre os países nâo-europeus quanto ao número de longevos ${ }^{3}$ e se coloca entre os líderes mundiais quanto à saúde da naçăo, dividindo com a Suécia e a Noruega o rol dos cinco países com a mais baixa taxa de mortalidade infantil.

Quando ocorreu a Revoluçáo, já existiam 13 países socialistas no mundo, principalmente na Europa e na Ásia, e isso permitiu que Fidel Castro analisasse suas experiências histórica, social, política e econômica. Entre os defeitos do modelo soviético, implantado na maioria dos países socialistas, Fidel destacou, em primeiro lugar, a burocratizaçáo excessiva da sociedade e a tendência do partido governante para se separar da vanguarda política, ou seja, do povo. Por isso, Fidel Castro se esforçou para criar um partido que estivesse indissoluvelmente ligado ao povo cubano. As primeiras organizaçóes do Partido Comunista de Cuba surgiram nas empresas que se tornaram principal palco de ação comunista para a ampliaçáo de suas fileiras. Hoje, o Partido é organizado a partir de diversos níveis: local (dentro de certo território e local de trabalho), municipal, provincial e nacional. Assim, as organizaçóes de base constituem o núcleo do organismo do Partido e permitem a captaçáo de novos militantes 
nas mais diversas camadas populacionais. Dessa forma, se mantêm sólidos vínculos entre o Partido e as massas trabalhadoras.

O cuidado para com as condiçổes de vida das pessoas comuns é a maior preocupaçáo do Partido Comunista de Cuba, que proclamou como seu objetivo político garantir a cada indivíduo uma vida sã e condigna, isenta, entretanto, de luxo e de prodigalidade, típicas de uma sociedade consumista que é incapaz de garantir a justiça social nem o progresso numa perspectiva de longo prazo. As tarefas de resistir ao modelo de sociedade consumista e seus valores e prioridades vitais e de ajustar as forças produtivas às necessidades de consumo da sociedade (o que, aliás, pode ser considerado como conquista da opçáo cubana) só podem ser cumpridas pelo próprio Estado e só por meio de coaçáo, através de uma economia planejada e dirigida. Nesse sentido, no primeiro plano se coloca a necessidade de dirigir cientificamente a economia, devendo essa meta tornar-se a principal preocupação do governo cubano na etapa atual. Diferentemente de Cuba, a URSS e os demais países socialistas da Europa seguiram, nas últimas três décadas, o padrăo de consumo e de qualidade da vida ocidental. Tal política provocou, em grande medida, a degeneraçáo dos regimes socialistas na URSS e nos países socialistas da Europa do Leste e, em última análise, seu desmoronamento nos anos 1990.

\section{Identidade: Um Estado Social ou Socialista?}

O conceito de Estado Social, inalienável do Direito e destinado a garantir a transiçáo gradual da sociedade aos princípios da igualdade, justiça e da moral, é um aspecto importante do modelo de nova sociedade criado com base no modelo de socialismo cubano. Nesse modelo, ocupam um lugar de destaque a consagraçáo e a concretizaçáo dos direitos constitucionais dos cidadãos à proteção social.

Verificamos com frequência no Direito moderno que as fórmulas de Estado Social e de Estado Socialista se encontram em contraposição. Alfonsas é daqueles que as considera contrapostas. Para Alfonsas, o Estado Social "se desenvolvia como alternativa ao Estado Socialista...”' . No entanto, uma análise etimológica das fórmulas supracitadas e dos fatos históricos refuta essas conclusóes. Primeiro, as palavras "social" e "socialista" derivam da mesma raiz e definem o objetivo comum desses Estados como primado dos benefícios sociais sobre os individuais ${ }^{5}$. Segundo, o termo social surgiu na prática constitucional muito antes do que o socialista. O especialista francês em Direito Marcel Preló $t^{6}$ registra as tentativas de qualificar a República como Estado Social ainda nos tempos da Reforma Constitucional de 1848, em contrapeso ao conceito de Estado-Guarda Nocturno baseado na ideologia do individualismo burguês. 
Mas o termo foi rejeitado pelas forças governantes como sendo proletário e refletindo os interesses do povo insurgido.

Só no século XX o termo social passou a ser correntemente usado pelos eurocomunistas e sociais democratas para realçar as diferenças entre os socialismos democrático e totalitário. Todavia, as diferentes visôes do papel do Estado na consecuçáo do bem-estar econômico e cultural do povo não excluem a afinidade entre o Estado Social e o Estado Socialista no aspecto principal, ou seja, no que se refere ao reconhecimento da responsabilidade do Estado pela existência da sociedade e pela vida condigna de todos os sócios que a compóem. Isso permite encarar os conceitos acima como termos constitucionais afins. Em alternativa ao Estado Social se encontra não tanto o Estado Socialista quanto, como antes, o Estado Capitalista de tipo liberal que serve unicamente aos interesses da cúpula governante e não se preocupa com as necessidades das demais camadas populacionais e em que a lei da obtençáo do lucro por todos os meios e sem quaisquer restriçóes sociais (ou comunitárias) é fundamental. Năo é à toa que o termo "socialista" em alguns países em desenvolvimento (a Síria, Argélia, Iêmen do Sul e outros) náo tem sido interpretado na acepçáo universal, à soviética, mas sim como sinônimo da natureza humanitária do Estado, voltada para a elevação dos padróes de vida das principais camadas da populaçăo.

\section{Século XXI: das Constituiçôes institucionais às Constituiçöes sociais}

Hoje em dia, observamos o aumento da tendência da transiçáo das Constituiçóes institucionais às Constituiçóes sociais: os países capitalistas adotam, a nível legislativo, o conceito de Estado Social. Já a Constituição mexicana de 1917, ainda vigente, em seu Artigo 3 consagra a "melhoria contínua dos padröes sociais e culturais da vida do povo", em seu Artigo 25 estabelece que o "Estado orienta o desenvolvimento nacional e garante seu caráter íntegro" e se refere à distribuiçáo justa das receitas entre os indivíduos, grupos e classes sociais e à justiça social e ao papel planejador do Estado.

A Constituiçáo de Weimar, aprovada na Alemanha em 1919, passou à posteridade como primeira Constituiçáo social do capitalismo (naquela altura, pouco se sabia sobre a Constituiçâo mexicana de 1917) a consagrar, pela primeira vez, o princípio: a propriedade obriga. A Lei Constitucional da Áustria, de 1920, acabou com os privilégios de classe. Encontramos disposiçóes semelhantes na Constituiçáo chilena de 1926. A Constituiçáo da Irlanda estabeleceu, em seu Artigo 43, entre outras coisas, que os direitos do proprietário devem ser regulados de acordo com o princípio da justiça social. 
A prática de introduzir em Constituiçóes os novos princípios do regime social e político, que podem ser qualificados como os do Estado Social, se tornou ainda mais intensa após a Segunda Guerra Mundial. O Preâmbulo da Constituiçấo da França, de 1946, atualmente em vigor como parte da Constituiçáo francesa consolidada, contém uma extensa lista de direitos econômicos e sociais, nấo excluindo a possibilidade da nacionalizaçáo, ou seja, a violaçáo do direito sagrado de propriedade proclamado dois séculos antes pela Declaraçăo dos Direitos do Homem e do Cidadáo, declaraçăo francesa de 1789.

A Constituição italiana, de 1947, atualmente vigente, estabelece em seu Artigo 42 que a propriedade privada é reconhecida e garantida pela lei, que determina seus limites, e em seu Artigo $41 \mathrm{diz}$ que a "atividade econômica pública e privada pode ser dirigida e coordenada para fins sociais". Também podemos citar disposiçóes semelhantes da Constituiçăo indiana de 1949, da Constituiçáo do Egipto de 1971, das Constituiçóes portuguesa de 1976 e espanhola de 1978 e de outras Leis Fundamentais aprovadas nos finais dos anos 1980, princípios de 1990 do século XX. As Constituiçóes mais recentes da Suíça, da Finlândia e da Venezuela, aprovadas em 1999, seguem o mesmo rumo. Algumas Constituiçóes dedicam capítulos inteiros à regulação das relaçóes sociais de modo semelhante. Por exemplo, os Capítulos Política, Economia, Cultura da Constituiçáo da República Democrática e Popular da Coréia, de 1972, o Capítulo A Sociedade e o Estado da Constituiçáo da Lituânia, de 1992, o Capítulo A Organizaçáo Econômica da Constituiçấo portuguesa, de 1976. A Constituição da Suíça, país tradicionalmente conservador, em seu Artigo 6, dispóe sobre os deveres do indivíduo perante a sociedade, a limitação da propriedade, em seu Artigo 26, as associaçóes de trabalhadores, em seu Artigo 28, a restriçâo dos direitos individuais em favor dos interesses públicos, em seu Artigo 38, e dedica um capítulo aos Fins Sociais.

Podemos constatar que os conceitos modernos de desenvolvimento da sociedade, do Estado e do Direito, legislativamente consagrados, ultrapassam os extremos do liberalismo individualista e avançam rumo ao Estado Social. O conceito de Estado Social surgiu em alguns países do Ocidente durante o processo de superaçáo de crises econômicas e socio-políticas, tendo sido teoricamente sintetizado e consagrado nas suas respectivas Constituiçóes vigentes. Esse conceito representa uma conquista teórica e prática do desempenho jurídico-institucional e constitui um fundamento teórico sério para buscas posteriores, dado que a "fórmula de Estado Social de Direito impóe a um legislador concreto uma exigência imperativa, e náo os meios nem orientaçóes imperativos de solução das tarefas". Os princípios sociais passam pela fixaçáo jurídica da responsabilidade do Estado de garantir os padróes de vida condignos e o livre desenvolvimento da personalidade, 
assim como pela concretizaçáo dessa sua responsabilidade em todos os níveis e ramos do Poder público. As atividades sociais de um Estado moderno, exercidas com base no princípio de sua auto-obrigaçáo unilateral, sáo objetivamente muito necessárias. Agindo desse modo, o Estado visa a redistribuiçáo justa dos benefícios econômicos, sociais e políticos de modo a que as pessoas carentes e menos abastadas sejam as que mais ganham com isso. Historicamente, a redistribuiçăo desse tipo é, não raro, declarada como justiça social. Esse tema ganhou maior atualidade face à presente crise financeira que é, principalmente, uma crise do sistema econômico capitalista, cuja lei fundamental é a obtençáo do lucro e superlucro apesar da situaçáo calamitosa das principais classes trabalhadoras e das camadas da sociedade.

\section{A Constituiçäo cubana de 1976: a fixação jurídica do modelo de socialismo nacional}

Nesse sentido, a Constituiçáo cubana de 1976 pode servir de exemplo, pois náo só proclamou a construção de um Estado Social mas também garantiu a implementaçáo prática desse objetivo.

Em 25 de fevereiro de 1975, a Comissáo de Redaçáo entregou a Fidel Castro o texto da proposta constitucional. Jurista de profissáo e estadista experiente, Fidel Castro contribuiu muito para a elaboraçăo de vários capítulos da Constituiçáo cubana. Por proposta sua, o texto da Constituiçấo foi submetido, em 1975, à uma consulta popular que envolveu cerca de 6,2 milhôes de cubanos. Muitas das sugestôes feitas pelo povo foram levadas em conta. A proposta constitucional foi submetida ao exame do I Congresso do Partido Comunista de Cuba. Ao discursar no Congresso, Fidel Castro assinalou que a

nova Constituiçáo destinada a substituir a Lei Fundamental de 1940 , que, muitas vezes alterada e emendada, vigorou até meados dos anos 70 , sintetiza a experiência de nosso povo e a experiência mundial dos povos que optaram antes de nós pelo caminho da construçáo de uma sociedade socialista. ${ }^{7}$

Fidel Castro deu especial ênfase à formaçáo de órgáos representativos do poder: a Assembléia Nacional do Poder Popular de Cuba, constituída por deputados, e assembléias do poder popular provinciais e municipais, constituídas por delegados que, tal como os deputados, sáo eleitos e cujo mandato pode ser revogado e que são obrigados a prestar contas aos eleitores, tal como, aliás, os juízes de todas as instâncias. Vale assinalar que, desde 1976, as eleiçóes de todos os níveis em Cuba têm tido vários candidatos, disputando-se uma vaga por vários concorrentes, o que náo se verificava em 
nenhum outro país socialista. O princípio da transparência do apuramento dos votos também contribuiu para a democratizaçáo das eleiçóes para deputado de todos os níveis.

Em 15 de fevereiro de 1976, a proposta constitucional foi submetida ao referendo nacional e aprovada pela maioria da populaçáo, entrando em vigor como nova Lei Fundamental em 24 de fevereiro desse mesmo ano. Fidel Castro escolheu a data de 24 de fevereiro para a proclamaçáo da nova Constituiçấo porque José Martí havia começado a guerra pela independência de Cuba em 24 de fevereiro de 1895.

O Capítulo I da Constituição Fundamentos Políticos, Econômicos e Sociais do Estado estipula, no Artigo 8, que o

Estado socialista realiza a vontade do povo trabalhador e canaliza os esforços da naçáo para a construçáo do socialismo; mantém e defende a integridade e a soberania da Pátria, garante a liberdade e a plena dignidade do homem, o desfrute de seus direitos, o exercício e o cumprimento de seus deveres e o desenvolvimento integral de sua personalidade; afiança a ideologia e as normas de convivência e de conduta próprias da sociedade livre da exploraçáo do homem pelo homem, protege o trabalho criador do povo e a propriedade e a riqueza da nação socialista; dirige planejadamente a economia nacional; assegura o avanço educacional, científico, técnico e cultural do país; como Poder do povo em serviço do próprio povo garante que nâo haverá homem ou mulher, em condiçóes de trabalhar, que não tenha a oportunidade de obter emprego com o qual possa contribuir para os fins da sociedade e para a satisfaçáo de suas próprias necessidades; que nảo haverá pessoa incapacitada para o trabalho que nắo tenha meios dignos de subsistência; que nấo haverá doente que náo tenha atenção médica; que não haverá criança que não tenha escola, alimentaçáo e vestido; que náo haverá jovem que náo tenha oportunidade de estudar; que nâo haverá pessoa que náo tenha acesso aos estudos, à cultura e ao esporte; trabalha para conseguir que não haverá família que nāo tenha habitação confortável. ${ }^{8}$

O Estado cubano oferece o ensino primário, secundário e superior gratuitos, a assistência médica gratuita, tendo efetivamente todas as camadas da populaçăo aceso à cultura, às artes e aos esportes. As habitaçóes são baratas e as tarifas dos serviços públicos são baixas. $\mathrm{O}$ desenvolvimento da economia visa o reforço do sistema socialista e uma melhor satisfação das necessidades materiais e culturais da sociedade e dos cidadáos e contribui para o desenvolvimento da personalidade e de sua dignidade, o progresso e a segurança do país e a capacidade da naçáo de cumprir o dever internacionalista de nosso povo. 
O Capítulo IV Educação e Cultura consagra os respectivos direitos sociais dos cubanos. O Artigo 38 garante o ensino gratuito e estabelece um amplo sistema de bolsas de estudo.

O Estado, a fim de elevar a cultura do povo, se ocupa de fomentar e desenvolver a educaçáo artística, a vocaçáo para a criaçáo e o cultivo da arte e a capacidade para a apreciar; a atividade criadora e investigadora na ciência é livre. $O$ Estado estimula e viabiliza a investigaçáo e prioriza aquela dirigida a resolver os problemas que atingem os interesses da sociedade e o benefício do povo. ${ }^{10}$

O Capítulo V Igualdade é um exemplo verdadeiramente inédito da atividade constitucional.

O Estado consagra o direito conquistado pela Revoluçăo de que os cubanos, sem distinçáo de raça, cor ou origem nacional: têm acesso, segundo méritos e capacidades, a todos os cargos e empregos do Estado, da Administraçắo pública e da produção e prestação de serviços; ascendem a todas as hierarquias das Forças Armadas revolucionárias e da segurança e ordem interna, segundo méritos e capacidades; recebem salário igual por trabalho igual; desfrutam de ensino em todas as instituiçôes de ensino do país, desde a escola primária até universidades que sáo as mesmas para todos; recebem assistência médica em todas as instalaçóes hospitalares. ${ }^{11}$

Note-se que o legislador nấo se limita à simples proclamaçâo do Estado Social. Ele formula o Capítulo VI Direitos, Deveres e Garantias Fundamentais, em que o trabalho é declarado como direito, dever e motivo de honra para cada cidadão.

O trabalho é remunerado conforme sua qualidade e quantidade; ao proporcioná-lo, se atende às exigências da economia e da sociedade, à escolha do trabalhador e sua aptidão e qualificaçấo; o direito ao trabalho é garantido pelo sistema econômico socialista que propicia o desenvolvimento econômico e social sem crises e com ele é eliminado o desemprego e apagada para sempre a parada estacional chamada "tempo morto"12. Todos os trabalhadores têm o direito ao descanso, à jornada de trabalho de oito horas e às férias pagas. Cuba é o único país do hemisfério ocidental a registrar o pleno emprego. Antes da Revoluçáo, um em cada três homens aptos para o trabalho năo tinha emprego e as mulheres estavam praticamente excluídas do processo de produção. Hoje em dia, $66 \%$ de todos os especialistas com cursos secundário e superior sâo mulheres ${ }^{13}$. Mediante o sistema de segurança social, o Estado garante a proteçáo adequada a todo o trabalhador impedido por sua idade, invalidez ou enfermidade. 
Entre outras garantias sociais concedidas pelo Estado, vale destacar a assistência social aos idosos náo aptos para o trabalho, a proteção, segurança e higiene do trabalho, a assistência médica gratuita em policlínicas e hospitais, a assistência estomatológica gratuita ${ }^{14}$. O direito à educação é garantido por uma rede de escolas gratuitas e de semi-internatos e internatos, por bolsas em todos os tipos e níveis de ensino e a gratuitidade do material escolar concedido a cada criança ou jovem, qualquer que seja a situaçáo econômica de sua família. Os homens e mulheres adultos desfrutam desse direito nas mesmas condiçóes da gratuitidade e com facilidades especiais, reguladas pela lei, mediante um sistema de educaçáo de adultos, ensino técnico e profissional, sua capacitaçăo laboral em empresas e organismos do Estado e cursos de ensino superior para os trabalhadores ${ }^{15}$.

A década de 1990 introduziu uma série de correçóes no modelo de socialismo cubano. A política de reforma traçada para 1991 pelo IV Congresso do Partido Comunista de Cuba ganhava força. Em 1992, a Assembléia Nacional fez emendas à Constituiçáa, segundo as quais foi reconhecido o direito de propriedade privada e mista. O Estado anunciou que só deixaria sob seu controle os setores básicos da economia, mantendo-se, contudo, fiel à ideia de construçáo de um Estado Social ${ }^{16}$, cujos cidadáos vivessem uma vida modesta mas condigna, estável e saudável, desfrutando de todas as conquistas da civilizaçáo moderna e preservando sua identidade nacional. Isso abre ao país um caminho para o futuro.

\section{Conclusão}

A análise da história do movimento de libertação revolucionário cubano e sua experiência de construçáo de uma sociedade baseada nos princípios da autêntica independência e justiça social leva a crer que o modelo de socialismo escolhido por Cuba é uma tentativa de levar à prática a ideia nacional, adequada às realidades internas e externas. A dignidade mencionada pelo destacado pensador, jurista e filósofo cubano José Martí teve concretizaçáo no modelo nacional de Estado Socialista (ou Social). Os cubanos entendem essa dignidade como justiça social, cultura de auto-limitaçáo, ética e moral, e náo como o aumento das riquezas individuais através da criaçăo de uma sociedade de consumo. $\mathrm{O}$ corredor das possibilidades para o desenvolvimento dentro do modelo escolhido teve sempre um espaço reduzido devido a muitos fatores internos e externos (o cerco mantido pelos EUA, a desagregaçáo do sistema socialista). O governo cubano precisava revelar uma flexibilidade excepcional e, ao mesmo tempo, a firmeza inabalável para não só concretizar, nas difíceis condiçóes sempre enfrentadas pela Revoluçáo cubana, a idéia nacional como também a defender com sucesso durante um período tâo longo. Apesar de todas as adversidades atuais, a alternativa social de Cuba à sociedade capitalista liberal continuará sendo um exemplo 
inspirador não só para os países da América Latina como também para muitos outros estados do mundo. É pouco provável alguém desejar copiar na íntegra o modelo cubano, mas o fato de, com a crise mundial de 2009, ter chegado a hora de estudá-lo a sério não é de duvidar.

\section{Notas e Referências}

1 Pensamiento politico, economico y social de Fidel Castro. La Habana, 1959, p. 7, 9.

2 Vide: "Cuba dos anos 90: modelo de economia de 'transiçáo' e a cooperaçáo com a Rússia". Os Cadernos Analiticos do Instituto de Estudos sobre a América Latina da Academia de Ciências da Rússia. 1998, n. 5.

3 Nos EUA, 77 anos, na Rússia, 67 anos.

4 V. ALFONSAS. O Estado Social de Direito; a realidade adquirida e perdida. Problemas jurídico-constitucionais da formaçáo de um Estado de Social de Direito. Os materiais da Conferência Internacional (Minsk. 30 a 31 de março de 2000). Mionsk, 2000, p. 24.

5 Sociale (do latim) significa "social".

6 M. PRELÓT. O Direito Constitucional de França. Traduçáo do francês de F. A. Kublitski. M., 1957, p. 350.

7 I Congresso do Partido Comunista de Cuba. Havana, 17 a 20 de dezembro de 1980. M., 1982, p. 113.

8 Gaceta Oficial de la Republica de Cuba. Edicion Especial, n. 2, de 24.II.1976; n. 18, de 29.VI.1978.

9 Ibid., p. 1611.

10 Ibid., p. 38.

11 Ibid., p. 42.

12 Ibid., p. 44.

13 Ibid., p. 46.

14 Ibid., p. 49.

15 Ibid., p. 50.

16 Em 2004, os gastos públicos com a educação, saúde, ciências, cultura, construçáo habitacional e os esportes atingiram $59 \%$ da Despesa Orçamentária. 